\title{
Evaluación del funcionamiento de un Generador de Ozono a escala piloto en la desinfección de agua para consumo humano
}

\author{
Alberto Galvis C.* \\ Guillermo Aponte M.** \\ Diego Fernando Echeverry I.*** \\ María Isabel González M.**** \\ Diana Amparo Cardona Z.*****
}

* M.Sc. Profesor Instituto Cinara - Facultad de Ingeniería Universidad del Valle - Santiago de Cali, Colombia. e-mail:algalvis@univalle.edu.co

** M.Sc. Director (e) Grupo GRALTA - Profesor Escuela de Ingeniería Eléctrica y Electrónica - Facultad de Ingeniería Universidad del Valle - Santiago de Cali, Colombia. E-mail:gponte@univalle.edu.co

$\star \star \star$ Ingeniero Electricista - Estudiante de Doctorado en Ingeniería - Asistente de Investigación Grupo GRALTA Facultad de Ingeniería - Universidad del Valle - Santiago de Cali, Colombia. e-mail: diecheve@univalle.edu.co

$\star \star \star \star$ Química - Universidad del Valle - Santiago de Cali, Colombia. e-mail:marabego@yahoo.com

$\star * * * *$ Ingeniera Sanitaria - Instituto CIMARA - Facultad de Ingeniería - Universidad del Valle - Santiago de Cali, Colombia. e-mail:diamcaze@hotmail.com
Fecha de recepción: Septiembre 14 de 2004

Fecha de aprobación: Junio 10 de 2005

\section{RESUMEN}

Este artículo presenta los resultados de la evaluación, al nivel de planta piloto, de un generador de ozono desarrollado en la Universidad del Valle por el grupo de Investigación GRALTA. La evaluación se realizó en la Estación de Investigación en Agua Potable de Puerto Mallarino del Instituto Cinara de la Universidad del Valle, en los diferentes niveles de riesgo que se presentan en un sistema de tratamiento de agua por Filtración en Múltiples Etapas FiME.

La evaluación del funcionamiento del generador de ozono se realizó con base en parámetros de producción continua de ozono, consumo de 
energía eléctrica y eficiencia del generador y costos de energía. Se tuvieron en cuenta además parámetros microbiológicos para evaluar la eficiencia en la desinfección y parámetros fisicoquímicos para el control del proceso.

Los resultados indicaron que el equipo generador tuvo una baja eficiencia en la producción de ozono. El efecto de la ozonización para la remoción de coliformes fecales, coliformes totales y color es más significativo en el efluente del filtro lento en arena (FLA), que en las etapas previas de tratamiento. Se lograron remociones significativas para hierro y manganeso en los efluentes del filtro grueso dinámico (FGDi) y el filtro grueso ascendente en capas (FGAC)

Palabras Clave: Desinfección de agua, generador de ozono, ozonización.

\section{ABSTRACT}

This paper presents the evaluation, at the level of a pilot plant, of an ozone generator developed in the Universidad del Valle by GRALTA research group. The evaluation was performed in Puerto Mallarino Water Supply Research Station of the Cinara Institute of the Universidad del Valle, for different risk levels present in a water treatment system by multistage filtration (MSF).

The evaluation of the ozone generator was carried out through operation parameters like ozone production, electric power consumption, generator efficiency, and energy costs. Microbiological parameters were measured to evaluate the disinfection efficiency and physical chemical parameters of the process control.

Results show that the ozone generator has a low efficiency in ozone production. The effect of the ozonation for fecal coliforms, total coliforms and color removal is more significant in a slow sand filtration (SSF) effluent, than in previous stages of treatment. Significant remotion levels were achieved for iron and manganese in the effluents from a dynamic-gravel-filter (DyGF) and a coarse-gravel filter with upflow layers.

Key Words: Disinfection of water, ozone generator, ozonation.

\section{INTRODUCCIÓN}

La desinfección es una de las principales etapas del proceso de potabilización de agua, indispensable para la eliminación de elementos patógenos que no fueron retenidos ni eliminados en las etapas previas del tratamiento y que pueden afectar la salud de los usuarios del sistema de abastecimiento.

Existen diferentes métodos para desinfectar el agua, cada uno de ellos con ventajas y desventajas (EPA, 1999; Solsona, 2002). El cloro en forma gaseosa es el desinfectante más utilizado en el mundo. Sin embargo, éste puede reaccionar con la materia orgánica que pueda encontrarse en el agua, generando subproductos como trihalometanos $\mathrm{y} / \mathrm{o}$ clorofenoles, considerados generadores de riesgo crónico debido a su posible efecto cancerígeno (Hoigne, 1993). La utilización del ozono como desinfectante primario o como oxidante en las etapas previas del tratamiento, es una alternativa a considerar para mejorar la calidad del agua que minimiza los riesgos generados en la desinfección con cloro

En consecuencia de lo anterior, los Grupos de Investigación de la Facultad de Ingeniería GRALTA (Grupo de Investigación en Alta Tensión) y CIMARA (Instituto de Investigación en Abastecimiento de Agua, Saneamiento Básico y Conservación del Recurso Hídrico), conscientes de la importancia de extender sus desarrollos tecnológicos para ponerlos al servicio de la sociedad, desarrollaron el proyecto "Uso del Ozono en la Desinfección de Agua para Consumo Humano", con apoyo de la Vicerrectoría de Investigaciones de la Universidad del Valle, en el período abril de 2003 - marzo de 2004.

Volumen 7 - No. 1 - Julio de 2005 
El proyecto tuvo por objeto evaluar al nivel de planta piloto, el funcionamiento de un generador de ozono desarrollado en la Universidad del Valle en un sistema de tratamiento de agua para consumo humano. La fase experimental del Proyecto se desarrolló en la Estación de Investigación en Agua Potable del Instituto Cinara, ubicada en los predios de la Planta de Tratamiento de Puerto Mallarino, de las Empresas Municipales de Cali, EMCALI en una planta piloto de Filtración en Múltiples Etapas FiME.

A través del estudio realizado se evaluó la eficacia del generador en la producción continua de ozono. Por otro lado se estudiaron las eficiencias del sistema de ozonización en la remoción de parámetros fisicoquímicos y microbiológicos, para diferentes niveles de riesgo sanitario, cuando se utiliza agua del Río Cauca a su paso por la ciudad de Cali.

Los resultados del proyecto contribuyen al estudio de la aplicación del ozono en proyectos a escala real, en comunidades donde el ozono se convierte en una alternativa sostenible para el mejoramiento de la calidad del agua de consumo.

\section{EXPERIMENTACIÓN}

\subsection{Descripción del sistema de ozonización}

El sistema de ozonización consta de un generador de ozono, una cámara de contacto y un dispositivo (filtro de carbón activado) que elimina el ozono que no se disuelve en el agua, tal como se muestra en la Figura 1.

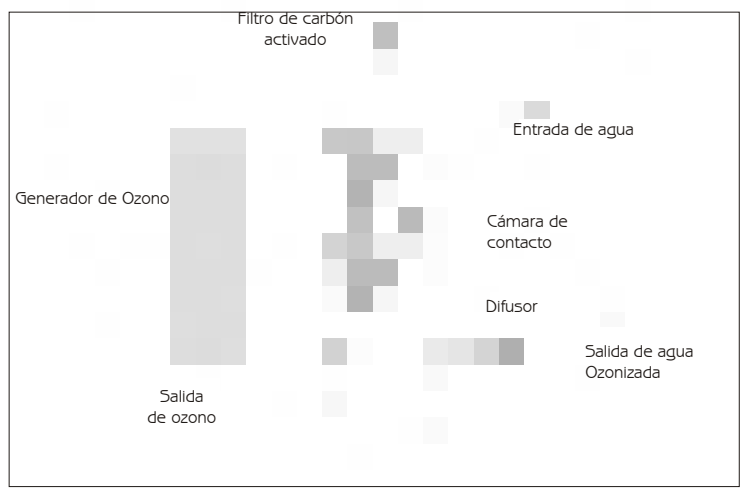

Figura 1. Sistema de Ozonización

\section{Generador de Ozono:}

El prototipo generador de ozono está conformado por tres partes: una fuente de alto voltaje, dos celdas de descarga corona con refrigeración y una unidad de tratamiento de aire. La etapa de tratamiento de aire y el circuito de control de voltaje se instalaron en un gabinete que tiene en su panel frontal los accesorios para operar el generador. En la Tabla 1 se describen las características de los componentes del generador y en la Figura $2 a$ se presenta una fotografía del prototipo generador de ozono.

En la Tabla 2 se presentan las especificaciones técnicas del generador de ozono. El rango de producción de ozono indicado en esta tabla, se obtiene por variación de voltaje.

Tabla 1 Características de los componentes del generador de ozono

\begin{tabular}{|c|c|}
\hline Componente & Características \\
\hline $\begin{array}{l}\text { Fuente de } \\
\text { Alto Voltaje }\end{array}$ & $\begin{array}{l}\text { El alto voltaje se obtiene de una fuente eléctrica variable, } \\
\text { conformada por un circuito electrónico para el control de } \\
\text { voltaje por ángulo de fase y un transformador elevador. } \\
(15 \mathrm{kV}, 250 \mathrm{kVA})\end{array}$ \\
\hline $\begin{array}{l}\text { Celdas de } \\
\text { Descarga }\end{array}$ & $\begin{array}{l}\text { El generador de ozono cuenta con dos celdas de descarga } \\
\text { de barrera dieléctrica, con dos electrodos cilíndricos coaxiales } \\
\text { de } 35 \mathrm{~mm} \text { de longitud, separados por un tubo dieléctrico de } \\
\text { vidrio Pirex de } 1,2 \mathrm{~mm} \text { de espesor y un gap de } 1,5 \mathrm{~mm} \text { de } \\
\text { ancho; El electrodo externo es de aluminio y el interno de } \\
\text { acero inoxidable. }\end{array}$ \\
\hline $\begin{array}{l}\text { Adecuación } \\
\text { del Aire }\end{array}$ & $\begin{array}{l}\text { El prototipo cuenta con dos bombas de membrana que } \\
\text { suministran, un flujo de } 10 \mathrm{l} / \mathrm{min} \text { de aire y una presión de } \\
5 \text { psi. } \\
\text { El aire bombeado se pasa por un filtro de sílica gel que } \\
\text { reduce la humedad relativa del aire al } 3 \% \text {. }\end{array}$ \\
\hline
\end{tabular}
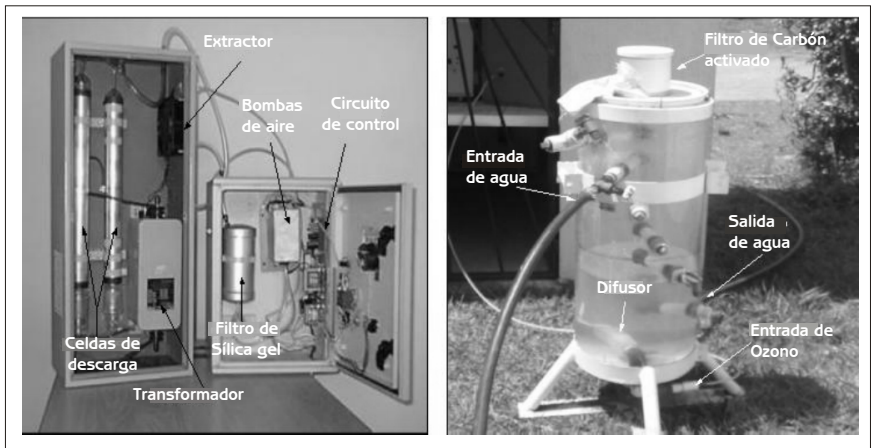

Figura 2. a) Generador de ozono. b) Cámara de contacto 
Tabla 2 Especificaciones técnicas del generador de ozono

\begin{tabular}{|l|l|}
\hline \multicolumn{1}{|c|}{ Parámetro } & Valor \\
\hline Voltaje de alimentación, $(\mathrm{V})$ & 120 \\
\hline Frecuencia, $(\mathrm{Hz})$ & 60 \\
\hline Corriente máxima, $(\mathrm{A})$ & 1,61 \\
\hline Producción de ozono, (g/h) & 01,5 \\
\hline Potencia activa, (W) & 88 \\
\hline Voltaje máx. en celdas, (KV) $^{\prime}$ & 15 \\
\hline Factor de Potencia, f.P & 0.449 \\
\hline Gas de alimentación $^{1}$ & - \\
\hline
\end{tabular}

${ }^{1}$ Aire Seco

\section{Cámara de Contacto:}

La cámara de contacto fabricada en acrílico, tiene $60 \mathrm{~cm}$ de altura y un diámetro de $30 \mathrm{~cm}$. En el fondo se ubicó un difusor rectangular de $15 \mathrm{~cm}$ de largo por $4 \mathrm{~cm}$ de lado. La cámara es hermética y tiene una salida superior a un filtro de carbón activo para el tratamiento del ozono gaseoso. El agua a tratar entra por la parte superior de la cámara y sale por el fondo con el fin de mejorar la transferencia del ozono en el agua. En la Figura 2b se presenta una fotografía de la cámara de contacto.

\subsection{Descripción del sistema de tratamiento de agua FiME:}

El sistema de tratamiento de agua de Filtración en Múltiples Etapas (FiME) consta de las siguientes barreras de tratamiento: Filtro Grueso Dinámico (FGDi), Filtro Grueso Ascendente en Capas (FGAC) y Filtro Lento en Arena ( $F L A)$.

\subsection{Montaje del experimento}

El sistema de ozonización fue instalado en el efluente de las unidades de tratamiento FiME:

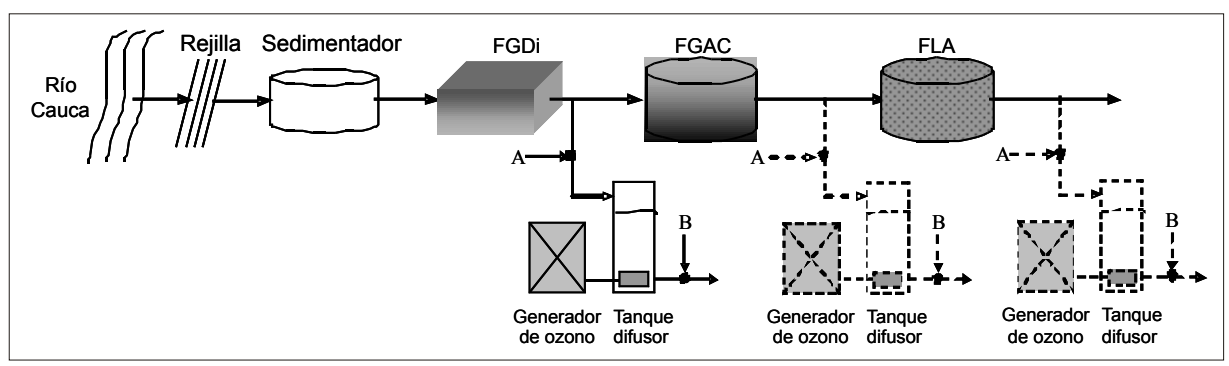

Figura 3. Esquema del sistema de tratamiento de la planta piloto y puntos de evaluación del generador de ozono
FGDi, FGAC y FLA. El tiempo de evaluación en cada una de estas unidades fue 6 semanas en el FGDi, 6 semanas en el FGAC y 3 semanas en el FLA. En la Figura 3 se presenta un esquema del sistema de tratamiento de la planta piloto $\mathrm{FiME}$, en donde se indican los puntos en los que se evaluó el funcionamiento del generador de ozono.

En cada unidad se definieron las condiciones en las cuales se realizaría la evaluación del generador. Para esto se efectuaron pruebas variando la producción de ozono y el tiempo de retención, con el fin de determinar la dosis de ozono requerida en el tratamiento. La Tabla 3 muestra las condiciones de operación del sistema de ozonización en las diferentes unidades del sistema de tratamiento de agua.

Tabla 3 Condiciones de operación del sistema de ozonización

\begin{tabular}{|l|l|c|c|c|}
\hline \multirow{2}{*}{ Parámetros } & \multicolumn{3}{|c|}{ Unidades de Tratamiento de Planta FiME } \\
\cline { 2 - 5 } & FGDi & FGAC & FLA \\
\hline \multicolumn{2}{|c|}{ Caudal (I/min) $)^{1}$} & 2.4 & 3.6 & 3.6 \\
\hline \multicolumn{2}{|l|}{ Tiempo de retención (min) } & 15 & 10 & 10 \\
\hline \multicolumn{2}{|c|}{ Dosis de ozono (mg//) $)^{2}$} & 3.47 & 2.31 & 2.31 \\
\hline \multirow{2}{*}{ Período } & $\begin{array}{l}\text { Ejecución de } \\
\text { experimentos }\end{array}$ & $\begin{array}{l}\text { Sept. 17 - } \\
\text { Oct. 30, 2003 }\end{array}$ & $\begin{array}{l}\text { Oct. 20 - Dic 3, } \\
\text { 2003 }\end{array}$ & $\begin{array}{l}\text { Dic. 4-30, 2003 } \\
\text { Feb. 25 - Mar. } \\
1,2004\end{array}$ \\
\cline { 2 - 5 } & Toma de muestra & 3/ semana & 4/ semana & 2/ semana \\
\hline
\end{tabular}

${ }^{1}$ Caudal afluente a la cámara de contacto del sistema de ozonización ${ }^{2}$ Producción de ozono aproximada: $500 \mathrm{mg} / \mathrm{h}$

${ }^{3}$ La ejecución de los experimentos inicia desde el momento en que se realiza la adecuación de las unidades de filtración

Para la evaluación de la capacidad de desinfección del generador de ozono se midieron los siguientes parámetros de calidad bacteriológica del agua: coliformes totales, coliformes fecales y además bacteriófagos, como un indicador de la remoción de virus. También se midieron parámetros de control como: alcalinidad, color, dureza, hierro, manganeso, nitratos, nitritos, pHy turbiedad.

La eficacia del equipo generador de ozono en la 
producción continua de las dosis, se evaluó mediante mediciones de la producción al inicio, durante y final de la experimentación, y mediciones de la concentración de ozono en agua durante el periodo de ozonización del efluente del FLA, donde los parámetros fisicoquímicos y microbiológicos presentaron poca variación. La determinación de ozono residual en agua se realizó según el método espectrofotométrico con el reactivo azul de índigo (American Public Health Association, 1992).

\section{RESULTADOS Y DISCUSIÓN}

\subsection{Evaluación del equipo generador de ozono}

\section{Producción continua de ozono}

La producción máxima de ozono fue de aproximadamente $1,5 \mathrm{~g} / \mathrm{h}$ cuando se suministraba aire seco a las celdas de descarga. Sin embargo, la producción máxima de ozono del equipo durante el periodo de evaluación fue de $500 \mathrm{mg} / \mathrm{h}$ y estuvo condicionada a la corta vida útil del filtro de sílica gel utilizado para el tratamiento del aire, el cual alcanzaba su nivel de saturación de humedad en un tiempo menor a 12 horas. Por tal razón, durante el experimento no fue posible suministrar aire con una humedad relativa constante.

En la Tabla 4 se presentan valores de producción de ozono a diferente humedad relativa y a 14,6 $k V$. Se puede observar que la producción de ozono es bastante sensible al cambio de la humedad relativa (HR) del gas de alimentación de las celdas.

Tabla 4 Producción de ozono a diferente humedad relativa del gas de alimentación.

\begin{tabular}{|c|c|}
\hline Producción $\left(\mathrm{mg} \mathrm{O}_{3} / \mathrm{h}\right)$ & Humedad Relativa $(\%)$ \\
\hline 1429 & 3 \\
\hline 867 & 30 \\
\hline 736 & 31 \\
\hline 661 & 33 \\
\hline 498 & 61 \\
\hline 453 & 63 \\
\hline
\end{tabular}

Según los resultados de la medición de producción de ozono al inicio, durante y al final del periodo de evaluación, se observa que el equipo generador de ozono entregó una dosis continua. En la Figura 4 se presentan dos curvas de la producción de ozono del equipo generador que se elaboraron al inicio y al final del periodo de evaluación. La diferencia que existe entre los valores de las dos curvas es inferior a $56 \mathrm{mg} \mathrm{O}_{3} / \mathrm{h}$, siendo en todos los casos, mayor la producción de ozono medida al final del periodo de evaluación. Esta diferencia puede atribuirse al efecto de la humedad relativa $y$ al cambio de electrodos que se realizó en la fase final de la experimentación.

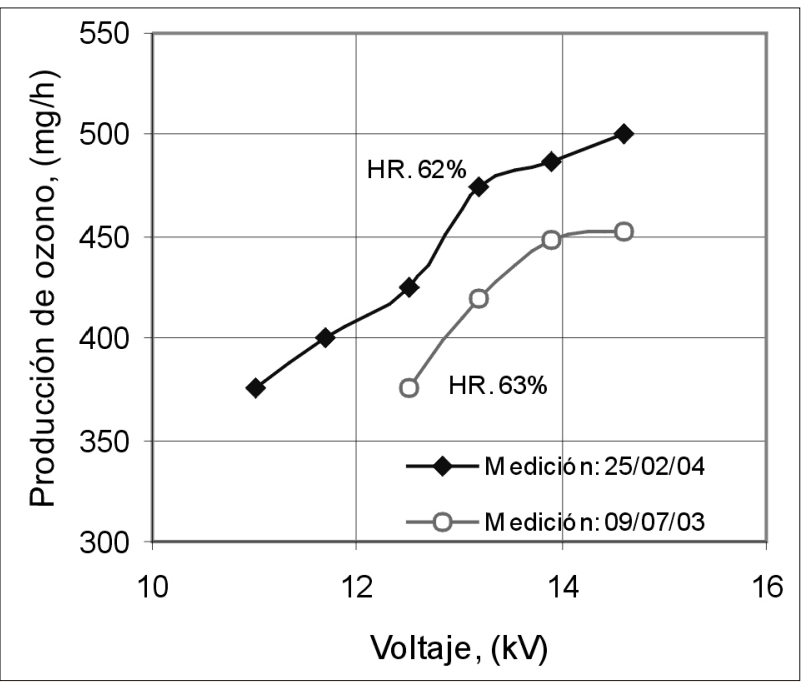

Figura 4 Producción de ozono al inicio y final de la experimentación

La continuidad en el suministro de la dosis de ozono, se puede verificar también, indirectamente, por medio de los valores de la concentración de ozono disuelto en el agua ozonizada; siempre que las características físicoquímicas y microbiológicas del agua y la eficiencia del sistema de contacto no varíen considerablemente. En este sentido, se pudo observar que la concentración de ozono en el agua durante la fase de ozonización del efluente del Filtro Lento en Arena ( $F L A$ ) se mantuvo entre $0.097 \mathrm{mg} \mathrm{O}_{3} / \mathrm{l}$ y $0.13 \mathrm{mg} \mathrm{O}_{3} / \mathrm{l}$. De lo anterior se 
puede inferir que en este último periodo de la evaluación, el equipo tuvo una producción de ozono relativamente estable.

Consumo de energía eléctrica y eficiencia del generador de ozono

La Tabla 5 presenta los valores de consumo de potencia activa del equipo generador para producción máxima.

Tabla 5 Consumo máximo de potencia activa del generador de ozono

\begin{tabular}{|l|c|}
\hline \multicolumn{1}{|c|}{ Componente } & Consumo de Potencia, $\mathbf{W}$ \\
\hline Celdas y transformador de alto voltaje & 54,5 \\
\hline Otros componentes & 33,5 \\
\hline Pérdidas del transformador & 4 \\
\hline Celdas & $50,5^{*}$ \\
\hline Consumo Total de Potencia Activa & 88 \\
\hline
\end{tabular}

*Valor calculado: (consumo celdas y transformador) - (pérdidas del transformador)

La energía suministrada a las celdas para una producción de 0,5g/h, fue de $101 \mathrm{~W}$-h/g. Según la teoría termoquímica, el valor teórico para el consumo de energía en la síntesis del ozono es de $0,822 \mathrm{~W}$-h/g, por lo cual, la eficiencia del equipo generador en función de este valor es del 0,8\%. Este resultado confirma la necesidad de optimizar el generador de ozono.

Costo del consumo de energía eléctrica

El costo de operación del generador se estimó con base en el consumo de energía eléctrica y fue calculado con base al precio del kW-h que las Empresas Municipales de Cali cobran a un usuario de estrato 3. Esta tarifa corresponde a $\$ 201 / \mathrm{kW}$ h. El Costo de funcionamiento fue de $\$ 425 /$ día.

El costo por día de funcionamiento del generador de ozono a máxima producción puede disminuir, conforme aumente su eficiencia en la producción.

\subsection{Análisis de parámetros microbiológicos y fisicoquímicos}

\section{Parámetros microbiológicos}

El mecanismo de desinfección de la ozonización se basa en el alto poder del ozono como oxidante protoplasmático, dando como resultado la desintegración de la pared de la célula. Sin embargo, en el efluente de la unidad de FGDi no se alcanzaron niveles significativos de remoción de coliformes totales y fecales. Se estima que esta situación muy posiblemente se debe a la presencia de sustancias fácilmente oxidadas por el ozono tales como: hierro, manganeso y a la elevada turbiedad del agua en este nivel de tratamiento. La Figura 4 muestra los resultados, las gráficas a y b se construyeron con base en las medianas de los datos.

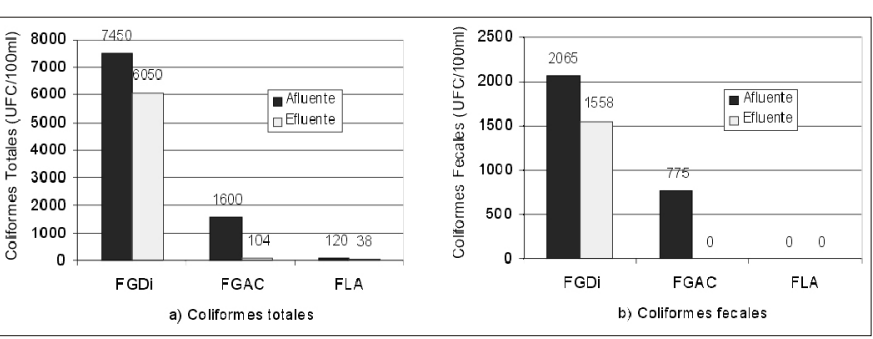

Figura 4 Evaluación de Coliformes Totales y Fecales en el efluente de las unidades de tratamiento FiME en el afluente y efluente de la ozonización

Tal como se muestra en la Figura 4, la eficiencia del ozono como desinfectante se empieza a evidenciar a partir de los resultados de calidad del efluente del FGAC, donde se obtuvieron remociones de coliformes totales entre 90\% 99.5\% y de coliformes fecales desde $99.5 \%$ y mayores a $99.99 \%$.

En el FLA la concentración de coliformes fecales fue removida casi en su totalidad cumpliendo con lo establecido en el Decreto 475 de 1998 del Ministerio de salud (Valor admisible de coliformes fecales $=0$ UFC/100 ml), sin embargo este nivel de remoción no se alcanza en el caso de los coliformes totales para los cuales el Decreto establece un valor admisible de coliformes totales $=0$ UFC $/ 100 \mathrm{ml}$. Estos resultados podrían optimizarse si se realizan algunas modificaciones en la unidad de difusión del ozono en el agua y la cámara de contacto.

Parámetros fisicoquímicos

El mayor efecto del ozono como oxidante puede ser observado en la remoción de hierro y 
manganeso en el efluente del FGDi. Las remociones fueron en hierro de $45 \%$ y en manganeso de $60 \%$. En la Figura 5 se muestran estos resultados. Se estima que la cinética de la reacción del ozono con los iones metálicos, es mayor que con las bacterias, por esta razón si el objetivo del tratamiento es la desinfección se deben eliminar o disminuir estos iones antes de la ozonización.

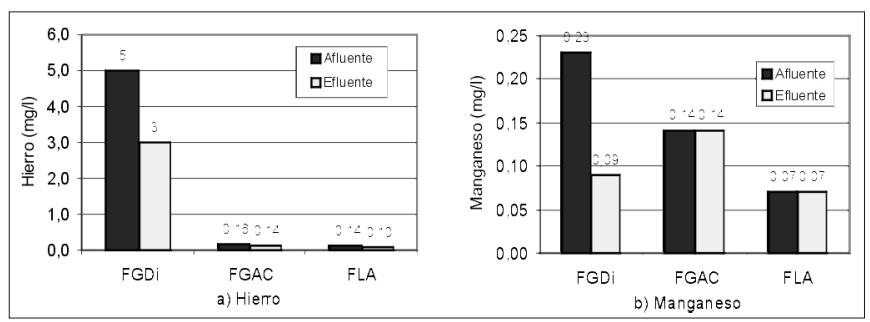

Figura 5 Remoción de hierro y manganeso.

La presencia de turbiedad en el agua disminuye la efectividad del ozono ya que ésta enmascara los microorganismos, limitando su acción bactericida. A medida que se avanza en las etapas del tratamiento ocurre una disminución en la turbiedad del agua afluente a las unidades FGDi, FGAC, y FLA del sistema de tratamiento. Sin embargo, no se presentan variaciones significativas de la turbiedad cuando se aplica ozono en el efluente de estas unidades de tratamiento.

Otros parámetros como el color real, la dureza, la alcalinidad y el $\mathrm{pH}$ no se vieron fuertemente afectados por el proceso de desinfección con ozono. Mo obstante se prevé que estos parámetros pueden afectar la efectividad de la desinfección.

\section{CONCLUSIONES}

च El generador de ozono fue efectivo en la producción continua de las dosis de ozono requeridas en los experimentos de ozonización del agua realizados en el marco del proyecto.

च La producción de ozono del equipo se ve disminuida hasta en un $66 \%$, cuando la humedad relativa del gas de alimentación aumenta del $3 \%$ al $62 \%$, mientras que el consumo de potencia se mantiene constante, confirmando así que es fundamental suministrar aire seco para la alimentación de las celdas de descarga para poder incrementar la eficiencia del generador de ozono.

च Se encontró que en la ozonización del efluente del Filtro Lento en Arena FLA, el costo por litro de agua tratada, asociado al consumo de energía eléctrica del generador de ozono, es de $0.119 \$ / l$. Se considera que este valor es bajo y se estima que se puede reducir aún más, aumentando la eficiencia del generador de ozono.

घ El sistema de control de voltaje por ángulo de fase utilizado en el generador de ozono fue efectivo para realizar a un bajo consumo de potencia, la variación de la producción de ozono, sin embargo, se considera conveniente evaluar nuevas tecnologías para un funcionamiento más eficiente del equipo.

■ La remoción de coliformes fecales y totales relacionadas con el efecto de la ozonización se presentó en cada uno de los efluentes de las unidades de FiME. Adicionalmente se encontró que la eficacia en la remoción mejora significativamente con la calidad fisicoquímica del efluente. Se estima que esta condición se da porque a medida en que se avanza en las etapas de tratamiento se tienen menos sustancias que demandan ozono.

$\square$ Para las condiciones del experimento, en la mayoría de los casos se logra la reducción total de coliformes fecales con la ozonización de los efluentes del FGAC y del FLA. El efecto más significativo en cuanto a remoción se presentó para el hierro y el manganeso, donde se alcanzaron, en el efluente del FGDi, remociones del $45 \%$ y $60 \%$ respectivamente.

$\square$ Se observó que el generador de ozono fue 
efectivo en la producción continua de las dosis de ozono requeridas en los experimentos de ozonización del agua realizados en el marco del proyecto. Sin embargo, se considera conveniente optimizar el diseño del generador, para lo cual será necesario realizar nuevas evaluaciones.

\section{BIBLIOGRAFÍA}

च American Public Health Association, Standard Methods, 18 ed, 1992. Washington, USA.

$\square$ EPA. Alternative Disinfectants and Oxidants. Guidance Manual, cap. 3. 1999

घ HOIGME, J. Characterization of Water Quality Criteria for Ozonation Processes. Minimal Set of Analytical Data. Ozone Science \& Engineering. Vol 16. 1993. P 113-120.

■ SOLSOMA, F. y MEMDEZ J. P. Desinfección del agua. Centro Panamericano de Ingeniería Sanitaria y Ciencias del Ambiente. 2002. Lima. Perú. 